\title{
Research on Commercial Vehicle Electronic Stability Control
}

\author{
Zhang Changlu ${ }^{1,2, a}$, Zhang Jingming ${ }^{1, \text { b, }}$, Zhang $\mathrm{Hao}^{2,3}$, \\ Zong Chengqiang ${ }^{2}$ and Zhang Hongwei ${ }^{2}$ \\ ${ }^{1}$ School of Automotive Engineering, Harbin Institute of Technology at Weihai, Weihai 264200, \\ China \\ ${ }^{2}$ Research Institute of Highway Ministry of Transport, Beijing100000, China \\ ${ }^{3}$ Transportation Vehicle Operation Safety Technology Key Laboratory of Transportation Industry, \\ Beijing100000, China \\ askyzcl6617@163.com \\ bwhjingming@163.com
}

\begin{abstract}
Based on the application of Electronic Stability Control in commercial vehicles, this paper proposes a control strategy on account of fuzzy PID control algorithm, and designs upper and lower double-layer controllers. The upper controller takes the error and change error of vehicle yaw rate as the input to design a yaw rate fuzzy PID controller, and takes the error and change error of vehicle slip-angle as the input to design a slip-angle fuzzy PID controller. The $\Delta \mathrm{M} \gamma$ and $\Delta \mathrm{M} \beta$ as the output of the yaw rate fuzzy PID controller and slip-angle fuzzy PID controller are calculated by the weighted module to calculate the additional yaw moment $\Delta \mathrm{M}$. The lower controller designs brake wheel selection module and brake force distribution module based on Matlab / Stateflow. With the co-simulation environment of Trucksim and Matlab/ Simulink, the paper conducts the typical condition simulation and evaluates the results. The results show that the dynamic response of yaw rate and slip-angle is improved when the vehicle, that is on the basis of the ESC control strategy designed in this paper, is undergoing simulation, which improves the driving stability of vehicles with low adhesion coefficient pavement.
\end{abstract}

Keywords: commercial vehicles, electronic stability control, fuzzy PID control, wheel selection algorithm, trucksim, co-simulation.

\section{Preface}

According to statistics, the number of accidents caused by commercial vehicles reached more than half of the China's major traffic accidents, of which nearly $30 \%$ of the accidents result from skidding, sharp turning and rollover. Electronic Stability Control can effectively control the occurrence of accidents caused by skidding, sudden turn and rollover. In terms of the ESC application, all new passenger cars and commercial vehicles registered in the EU must be equipped with ESC, starting from November 2011[1] ;but the ESC are only applied part of the high-end sedan in China, commercial vehicles don't install the ESC.

Many researchers have made great contribution on the study of the control strategy of the Electronic Stability Control. TCHAMNA [2] proposed a control method of vehicle yaw rate and slip-angle, taking into account the longitudinal dynamic characteristics of the vehicle without the need for assumptions on the vehicle's motion state. Fu Hao [3] analyzed the vehicle stability and its characterization state and designed ESC control algorithm combining the PID and logic threshold Algorithm, based on the stability boundary of vehicle yaw rate and slip-angle. Other researchers also have done many research on ESC control strategy [4-5].

However, most of the research on ESC is for passenger cars, less on commercial vehicles in China. In this paper, we design an ESC fuzzy PID double-layer controller for the commercial vehicle, and 
conducted co-simulation on the basis of simulation environment built by the Trucksim and Matlab/Simulink [6].

\section{Building reference model}

According to vehicle dynamics, the vehicle is simplified, and a 2-DOF reference model is obtained, as shown in Fig. 1. The expected value of vehicle yaw rate and slip-angle can be obtained from the 2-DOF model of the vehicle.

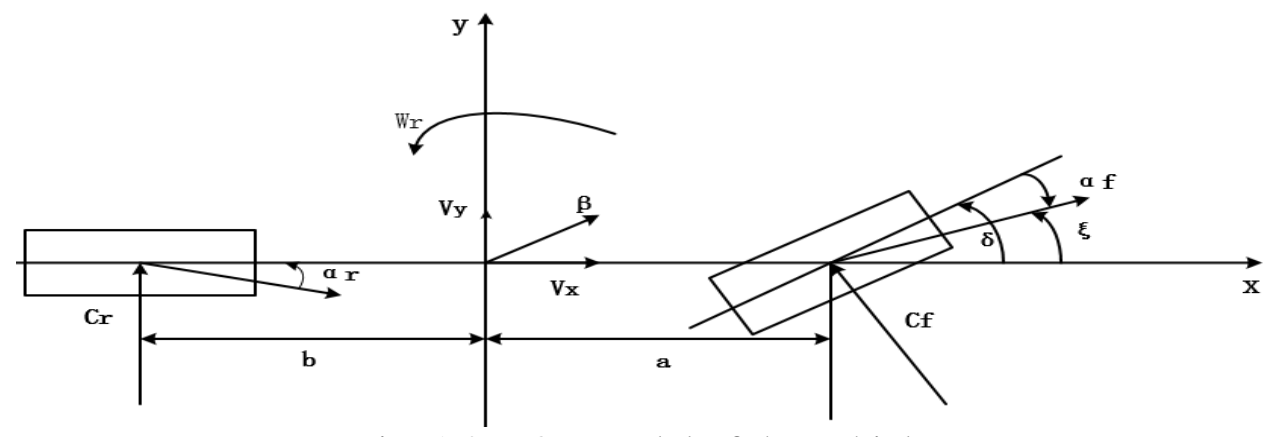

Fig. 1 2-DOF model of the vehicle

With the rigid-body dynamics and the force analysis in Figure 1, the longitudinal force and the centroid moment are got:

$$
\left\{\begin{array}{c}
\sum \mathrm{F}_{\mathrm{Y}}=\mathrm{C}_{\mathrm{f}} \cos \delta+\mathrm{C}_{\mathrm{r}} \\
\sum \mathrm{M}_{\mathrm{Z}}=\mathrm{a} \mathrm{C}_{\mathrm{f}} \cos \delta-\mathrm{b} \mathrm{C}_{\mathrm{r}}
\end{array}\right.
$$

Taking the smaller $\delta$ and kinematics theory into account, equation (1) can be transformed into equation (2):

$$
\left\{\begin{array}{l}
\left(\mathrm{k}_{1}+\mathrm{k}_{2}\right) \beta+\frac{1}{\mathrm{v}_{\mathrm{x}}}\left(\mathrm{ak}_{1}-\mathrm{bk}_{2}\right) \mathrm{w}_{\mathrm{r}}-\mathrm{k}_{1} \delta=\mathrm{m}\left(\dot{\mathrm{v}}_{\mathrm{y}}+\mathrm{v}_{\mathrm{x}} \mathrm{w}_{\mathrm{r}}\right) \\
\left(\mathrm{a} \mathrm{k}_{1}-\mathrm{bk}_{2}\right) \beta+\frac{1}{\mathrm{v}_{\mathrm{x}}}\left(\mathrm{a}^{2} \mathrm{k}_{1}+\mathrm{b}^{2} \mathrm{k}_{2}\right) \mathrm{w}_{\mathrm{r}}-\mathrm{a} \mathrm{k}_{1} \delta=\mathrm{I}_{\mathrm{Z}} \dot{\mathrm{w}}_{\mathrm{r}}
\end{array}\right.
$$

m--Vehicle quality; $v_{x}, v_{y}$--Longitudinal and lateral speed; a, b--Front and rear wheelbase;

$\beta$--Slip-angle; $w_{r}$-- Yaw rate; $\delta$--Front wheel angle; $C_{f}, C_{r}$--Moment of inertia around the $\mathrm{Z}$ axis;

$k_{1}, k_{2}$--Front and rear wheel cornering stiffness;

\section{Design of Commercial Vehicle Electronic Stability Control}

In this paper, Taking the vehicle yaw rate and slip-angle as the control variable, the hierarchical control system is designed as is shown in Fig. 2.

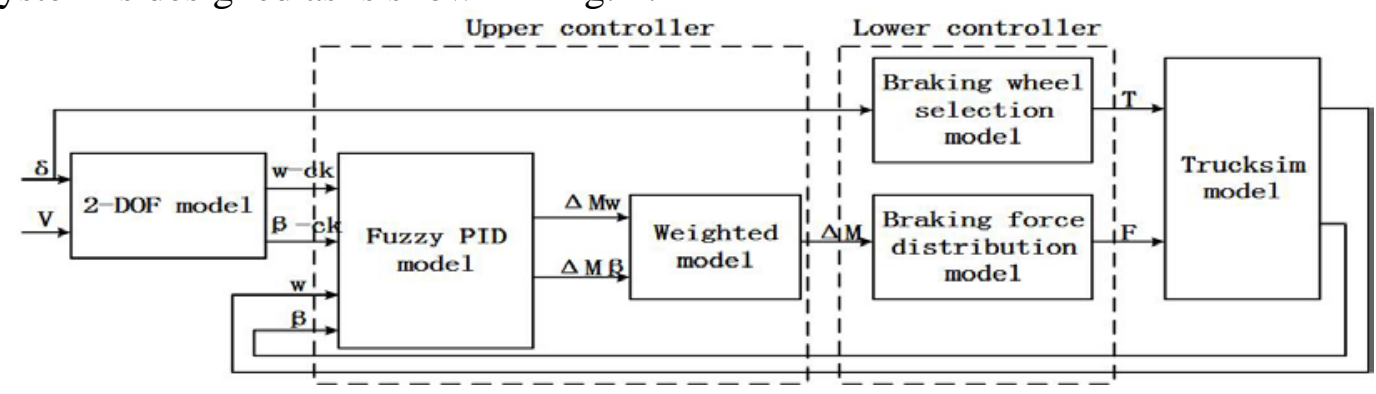

Fig. 2 The controlling schematic diagram

\subsection{The Upper Controller}

\subsubsection{The Fuzzy PID Model}

The fuzzy PID controller is composed of the yaw rate fuzzy PID controller and the slip-angle fuzzy PID controller, as is shown in Fig. 3. 


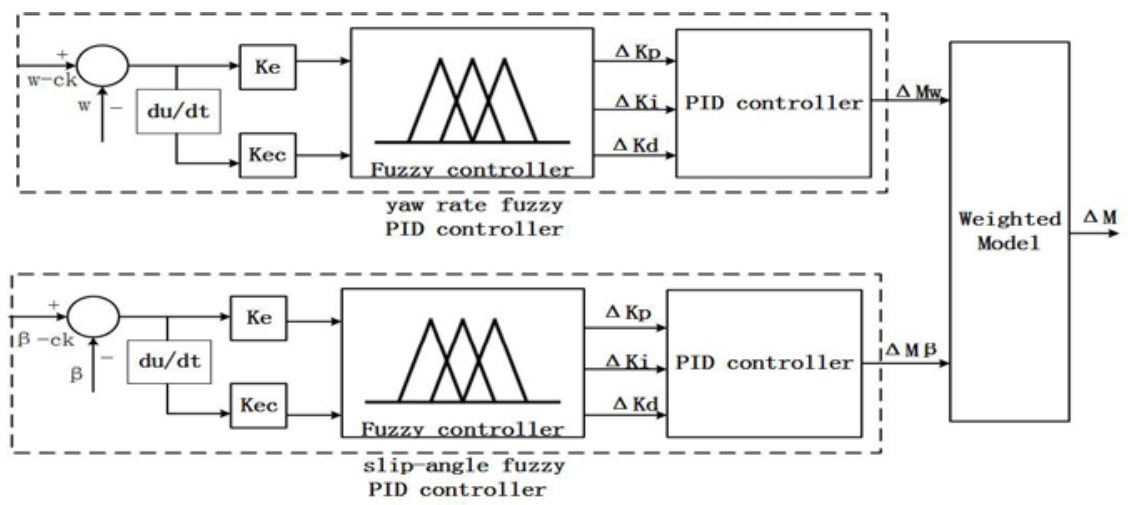

Fig. 3 The upper controller structure diagram

Because the design principles of the yaw rate fuzzy PID controller and the slip-angle fuzzy PID controller are the same, the slip-angle PID controller will only be explained in detail here. First of all, in the fuzzy controller, the error and the change error of the slip-angle are taken as the input. The PID control proportional parameter $\Delta \mathrm{K}_{\mathrm{p}}$, the integral parameter $\Delta \mathrm{K}_{i}$ and the differential parameter $\Delta \mathrm{K}_{\mathrm{d}}$ are the output. $\Delta \mathrm{K}_{\mathrm{p}}, \Delta \mathrm{K}_{i}$ and $\Delta \mathrm{K}_{\mathrm{d}}$ are put into the PID Controller to adjust the value of $\mathrm{K}_{\mathrm{p}}, \mathrm{K}_{\mathrm{i}}$ and $\mathrm{K}_{\mathrm{d}}$. Finally, taken as the additional yaw moment, the $\Delta \mathrm{M} \beta$ is put out.

The theoretical value of the error and change error is [-6,6]. The theoretical value of the $K_{p}, K_{i}$ and $K_{d}$ is $[-3,3]$. The fuzzy controller adopts seven linguistic variables, the fuzzy subset of input and output variables is $\{\mathrm{NB}, \mathrm{NM}, \mathrm{NS}, \mathrm{ZO}, \mathrm{PS}, \mathrm{PM}, \mathrm{PB}\}$. In this paper, the membership function of the fuzzy subset is chosen to be the triangular membership function, as is shown in Fig. 4 and Fig. 5.

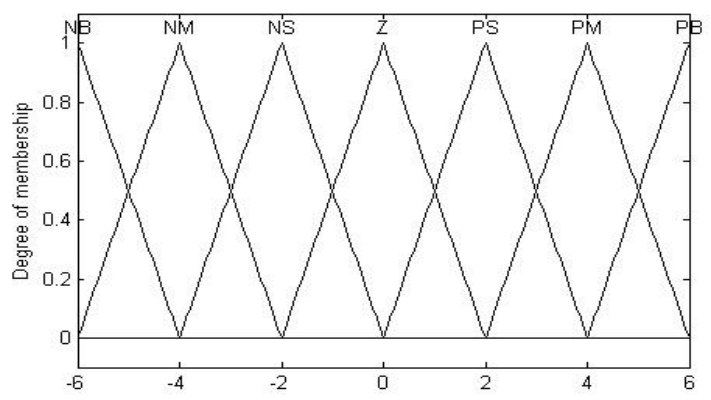

Fig. 4 The membership function of $\mathrm{K}_{\mathrm{p}}, \mathrm{K}_{\mathrm{i}}$ and $\mathrm{K}_{\mathrm{d}}$

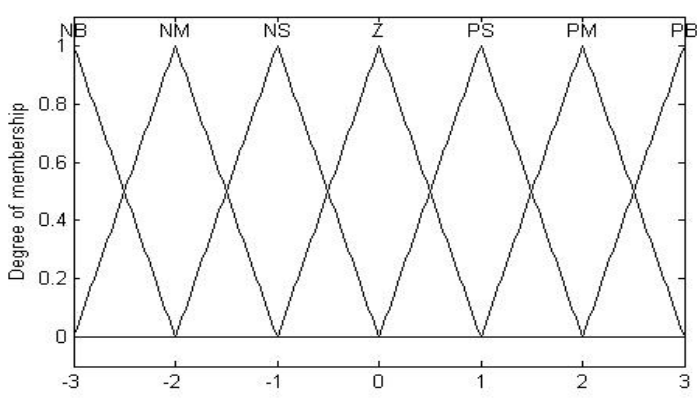

Fig. 5 The membership function of e and ec

Based on the expert's experience and "Mamdani" theory, this paper sets up 49 logic control rules for $\mathrm{K}_{\mathrm{p}}, \mathrm{K}_{\mathrm{i}}$ and $\mathrm{K}_{\mathrm{d}}$ respectively, as is shown in Table 1.

Table 1 Control rules table

\begin{tabular}{|c|c|c|c|c|c|c|c|c|}
\hline \multirow{2}{*}{\multicolumn{2}{|c|}{$\Delta K_{p} / \Delta K_{i} / \Delta K_{d}$}} & \multicolumn{7}{|c|}{ ec } \\
\hline & & NB & NM & NS & $\mathrm{ZO}$ & PS & PM & PB \\
\hline \multirow{7}{*}{ e } & NB & $\mathrm{PB} / \mathrm{NB} / \mathrm{PS}$ & $\mathrm{PB} / \mathrm{NB} / \mathrm{NS}$ & $\mathrm{PM} / \mathrm{NM} / \mathrm{NB}$ & $\mathrm{PM} / \mathrm{NM} / \mathrm{NB}$ & PS/NS/NB & $\mathrm{ZO} / \mathrm{ZO} / \mathrm{NM}$ & $\mathrm{ZO} / \mathrm{ZO} / \mathrm{PS}$ \\
\hline & NM & $\mathrm{PB} / \mathrm{NB} / \mathrm{PS}$ & $\mathrm{PB} / \mathrm{NB} / \mathrm{NS}$ & $\mathrm{PM} / \mathrm{NM} / \mathrm{NB}$ & PS/NS/NM & PS/NS/NM & $\mathrm{ZO} / \mathrm{ZO} / \mathrm{NS}$ & $\mathrm{NS} / \mathrm{ZO} / \mathrm{ZO}$ \\
\hline & NS & $\mathrm{PM} / \mathrm{NB} / \mathrm{PS}$ & $\mathrm{PM} / \mathrm{NM} / \mathrm{NS}$ & $\mathrm{PM} / \mathrm{NS} / \mathrm{NM}$ & $\mathrm{PS} / \mathrm{NS} / \mathrm{NM}$ & $\mathrm{ZO} / \mathrm{ZO} / \mathrm{NS}$ & NS/PS/NS & NS/PS/ZO \\
\hline & $\mathrm{ZO}$ & $\mathrm{PM} / \mathrm{NM} / \mathrm{ZO}$ & $\mathrm{PM} / \mathrm{NM} / \mathrm{NS}$ & PS/NS/NS & $\mathrm{ZO} / \mathrm{ZO} / \mathrm{NS}$ & NS/PS/NS & NS/PM/NS & NM/PM/ZO \\
\hline & PS & PS/NM/ZO & PS/NS/ZO & $\mathrm{ZO} / \mathrm{ZO} / \mathrm{ZO}$ & NS/PS/ ZO & NS/PM/ZO & NS/PM/ZO & NM/PM/ZO \\
\hline & PM & PS/ZO/PM & $\mathrm{ZO} / \mathrm{ZO} / \mathrm{PS}$ & NS/PS/ PS & NS/PS/ PS & NS/PM/ PS & NM/PB/PS & NB/PB/PM \\
\hline & PB & $\mathrm{ZO} / \mathrm{ZO} / \mathrm{PB}$ & ZO/PS/PM & NM/PS/ PM & NM/PM/ PS & NM/PM/ PS & NM/PB/PS & NM/PB/PB \\
\hline
\end{tabular}

\subsubsection{The Weighted Model}

The weighted model is designed to weight the $\Delta \mathrm{M} \gamma$ from the yaw rate controller and the $\Delta \mathrm{M} \beta$ from the slip-angle controller to achieve the coordinated control. The formula is as the following:

$$
\Delta \mathrm{M}=(1-\mathrm{K}) \Delta \mathrm{M}_{\gamma}+\mathrm{K} \Delta \mathrm{M}_{\beta}
$$




\subsection{The Lower Controller}

\subsubsection{The Design of Brake Wheel Selection}

According to the relationship between each wheel and the yaw moment, wheel selection rules table is designed, as is shown in Table 2. The left turn is positive, and the counterclockwise direction of yaw rate is positive.

Table 2 Wheel selection rules table

\begin{tabular}{|c|c|c|c|}
\hline Front wheel angle & Yaw rate error & Vehicle state & Brake wheel \\
\hline$\delta \geq 0$ & $\mathrm{e}>0$ & Left under-steering & Left rear wheel \\
\hline$\delta \geq 0$ & $\mathrm{e}<0$ & Left over-steering & Right front wheel \\
\hline$\delta<0$ & $\mathrm{e}>0$ & Right over-steering & Left front wheel \\
\hline$\delta<0$ & $\mathrm{e}<0$ & Right under-steering & Right rear wheel \\
\hline- & $\mathrm{e}=0$ & steady & No control \\
\hline
\end{tabular}

\subsubsection{The Design of Braking Force Distribution Control}

There are two main control methods for the lower controller: the first one is controlled by the slip rate controller and the second is the direct yaw moment control [7]. This paper uses the latter, that is, the additional yaw moment is translated into the braking force of the wheel to control stability.

Taking the left turning as an example, the theory is introduced. When the vehicle is in an unstable state, by applying braking force for the wheel to generate additional yaw moment, the vehicle returns to the steady state. Fig. 6 (a) shows the force analysis of braking the left rear wheel when the vehicle is under-steering, and Fig. 6 (b) shows the force analysis of braking the right front wheel when the vehicle is over-steering.

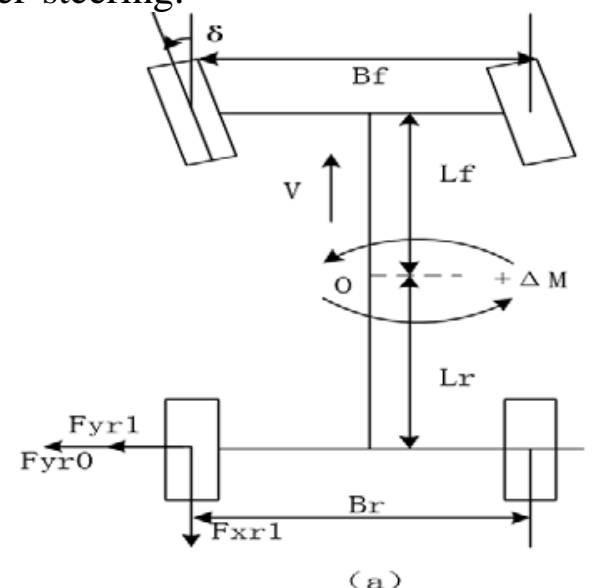

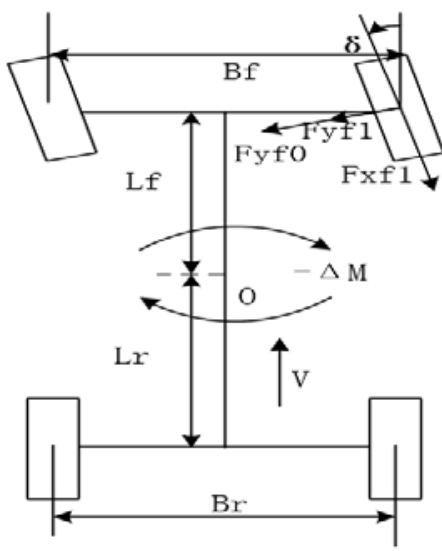

(b)

Fig. 6 The force analysis of direct yaw moment control

As is shown in Figure 6 (a), when the vehicle is understeering, by applying instantaneous braking to the left rear wheel, the braking force increases, the lateral force decreases, and the yaw moment is redistributed. The additional yaw moment that the two force produce, causes the vehicle to restore the stability. The additional yaw moment is shown in the following formula:

$$
\Delta \mathrm{M}=\left(\mathrm{F}_{\mathrm{xr} 1}-\mathrm{F}_{\mathrm{xr} 0}\right) \frac{\mathrm{B}_{\mathrm{r}}}{2}-\left(\mathrm{F}_{\mathrm{yr} 1}-\mathrm{F}_{\mathrm{yr} 0}\right) \mathrm{l}_{\mathrm{r}}
$$

Ignoring the impact of related factors, the above formula can be rewritten as the following:

$$
\Delta \mathrm{M}=\mathrm{F}_{\mathrm{xr} 1} \frac{\mathrm{B}_{\mathrm{r}}}{2}
$$

So, additional yaw moment translated into a single wheel brake force is the following:

$$
\mathrm{F}=\frac{2 \Delta \mathrm{M}}{\mathrm{B}_{\mathrm{r}}}
$$

\section{Simulation analysis}

With the co-simulation environment of Trucksim and Matlab/ Simulink, the paper conduct the typical condition simulation and evaluates the results [8]. The co-simulation model is shown in Fig. 7. This paper establishes a complex non-linear model to simulate the actual vehicle on the basis of Trucksim, and builds the ESC system based on Matlab/Simulink. 


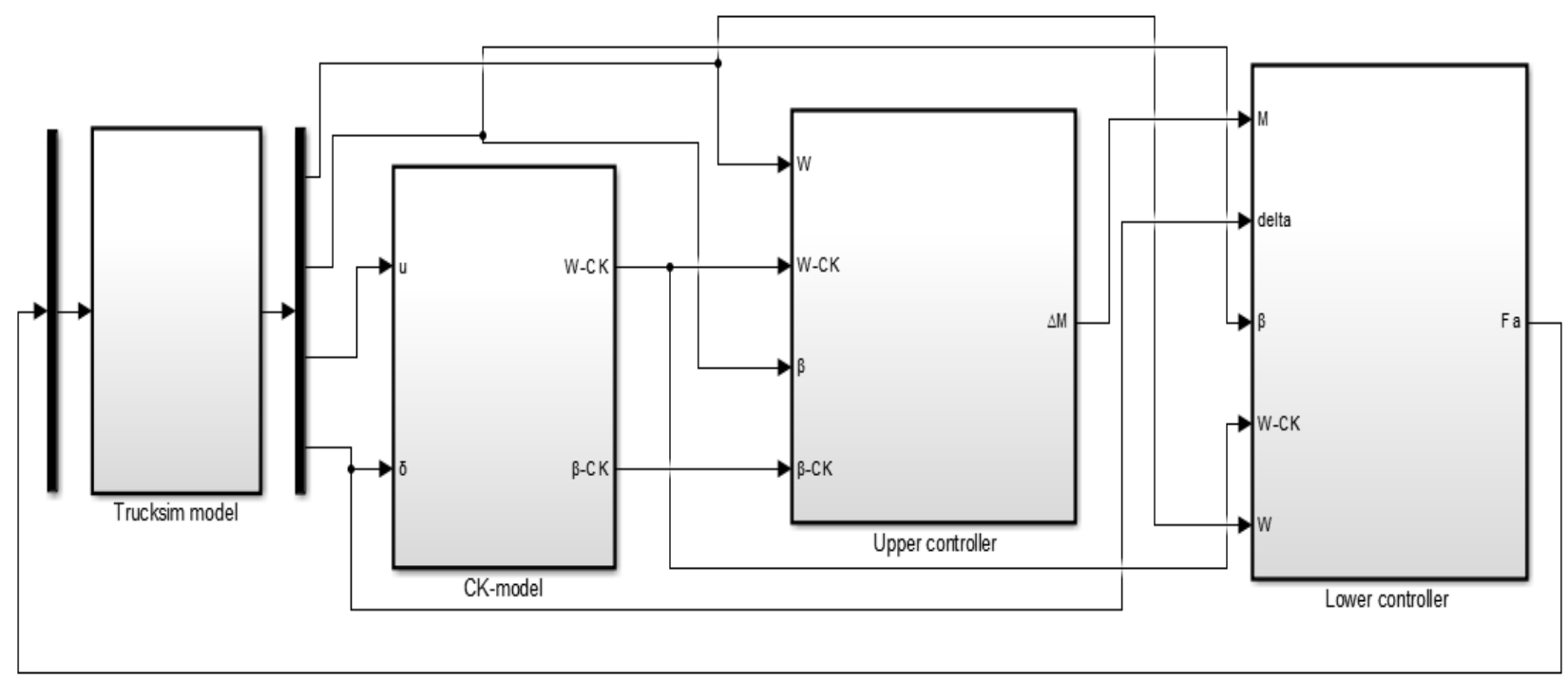

\subsection{Fish-Hook}

Fig. 7 The co-simulation model

The Fish-Hook test is a typical lateral stability in Trucksim. The coefficient of road adhesion is 0.3 , the speed is $70 \mathrm{~km} / \mathrm{h}$. The test is mainly done by setting the steering wheel angle to verify the stability of the vehicle during the turning.

Through the co-simulation, the vehicle yaw rate transient response curve and the slip-angle transient response curve are obtained, as is shown in Fig. 8 and Fig. 9. It is shown in the figure that nearly 3s,the yaw rate and the slip-angle increase significantly in the absence of control, and the vehicle occurs slipping; After adding the ESC, the overshoot of yaw rate and slip-angle is reduced, the dynamic characteristics become stable and the experiment can be completed normally.

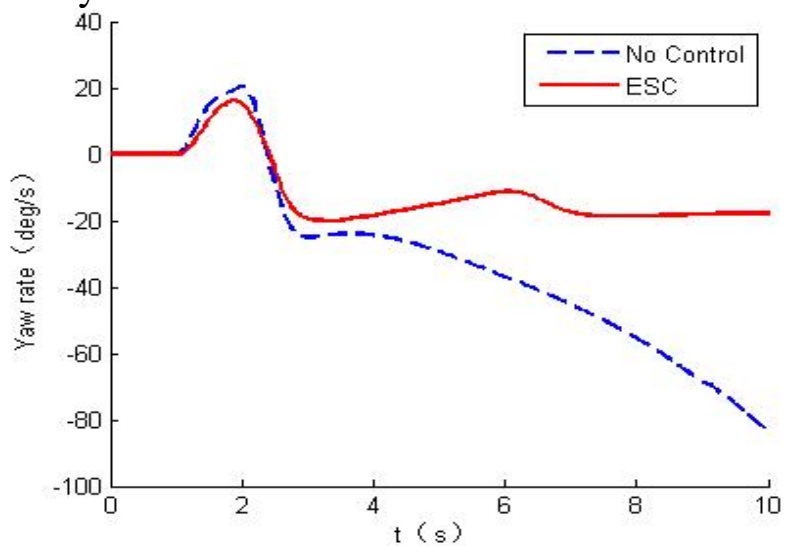

Fig. 8 The yaw rate transient response curve

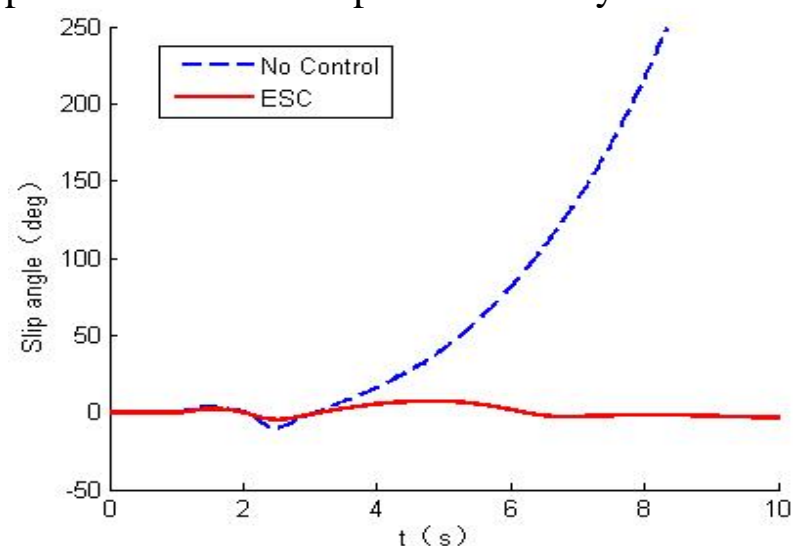

Fig. 9 The slip-angle transient response curve

\subsection{Double Lane Change}

The Double Lane Change test is a steering system closed-loop test in Trucksim which allows the driver to adjust the steering wheel angle based on the path that has been set. The coefficient of road adhesion is 0.3 , the speed is $80 \mathrm{~km} / \mathrm{h}$.

The vehicle yaw rate transient response curve and the slip-angle transient response curve are shown in Fig. 10 and Fig. 11. As is shown in Fig. 10, under the current condition, the yaw rate of the vehicle fluctuates largely in the absence of control and reaches $15.9 \mathrm{deg} / \mathrm{s}$ at $6 \mathrm{~s}$; At $7.7 \mathrm{~s}$, the yaw rate reaches $27.5 \mathrm{deg} / \mathrm{s}$, the vehicle loses its stability and deviates from the lane. Under the control of the ESC, the vehicle suppresses the fluctuation of the yaw rate and the vehicle can finish the test well following the set route. 


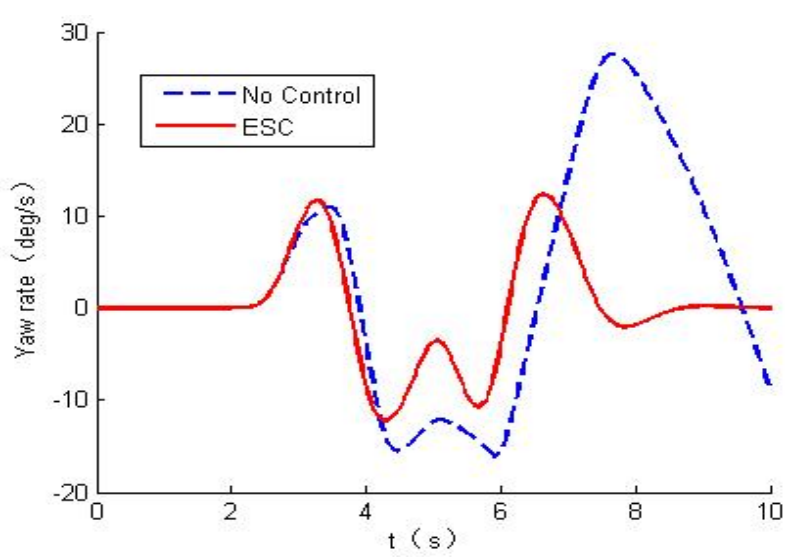

Fig. 10 The yaw rate transient response curve

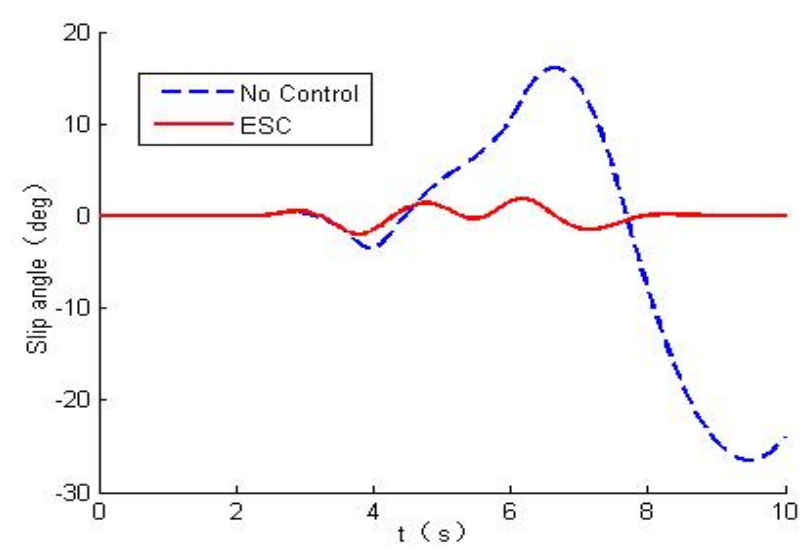

Fig. 11 The slip-angle transient response curve

\section{Conclusion}

The results of Fish-Hook and Double lane change show that vehicles are prone to slip and lose stability under low adhesion road and high speed. The proposed ESC control strategy based on fuzzy PID control algorithm has good transient response capability and dynamic control performance. Through the direct yaw moment control, the yaw rate fluctuation can be effectively restrained, and the slip-angle is maintained within the ideal range, so that the vehicle can maintain a steady state and the stability of the commercial vehicle under low adhesion road conditions can be effectively improved.

\section{Acknowledgments}

This work was financially supported by the project of exchange box size and general requirements $\mathrm{C}$ series research, the project number is Z2140199160550873.

\section{References}

[1] Karush S. Truck Tractors, Buses Could Get Standard ESC under NHTSA Proposal [J]. Status Report, 2012, 47.

[2] TCHAMNA R, YOUN I. Yaw rate and side-slip control considering vehicle longitudinal dynamics [J]. International Journal of Automotive Technology, 2013, 14(1):53-60.

[3] Fu Hao. Research on Sideslip Angle Estimation and Control Algorithm for Vehicle Electronic Stability System [D] .Jilin University, 2008.

[4] Rao S J, Salaani M K, Elsasser D, et al. Scenario Regeneration using a Hardware-in-the-loop Simulation Platform to Study ABS and ESC Performance Benefits[C] SAE 2015 Commercial Vehicle Engineering Congress. 2015.

[5] ZHAO Shuen, LI Yinong, ZHENG Ling, et al. Vehicle lateral stability control based on sliding model control[J].

[6] Wei C Y, Long Z Y, Xie L, et al. Tractor-Semitrailer Stability Integrated Control Based on TruckSim-Simulink Co-Simulation [J]. Advanced Materials Research, 2014, 945-949:1539-1542.

[7] YU Zhuoping, GAO Xiaojie, ZHANG Lijun. A study on coordination of direct yaw moment control and variable wheel slip control for vehicle stability [J]. Automotive Engineering, 2006, 28(9):844-848.

[8] GUO Konghui, FU Hao, HU Jin, et al. Simulation application of test and evaluation methods on electronic stability control [J]. Automobile Technology, 2008, 10(10):1-15. 